\title{
FACES DA AVALIAÇÃO NO TREINAMENTO COLABORATIVO ${ }^{1}$
}

\section{FACES OF ASSESSMENT IN COLLABORATIVE TRAINING}

\section{Jairit Garavit ${ }^{2}$}

https://orcid.org/0000-0003-1976-9891

1. ¿Este produto é o resultado do trabalho árduo de uma de suas Linhas de Pesquisa do projeto "Como deve pesquisar em Educação virtual e a distância?" do ano de 2021, realizada com Membros de forma interdisciplinar e interinstitucional (Professores - Alunos) da Pesquisa Seedbed: Sistemas Integrados de Gestão "Integradoss" Anexados ao GrupLAC: SIGCIENTY da Universidade Nacional Aberta e a Distância UNAD.

2. Engenheiro Industrial, Especialista em Educação Superior e à Distância, Mestre em Sistemas Integrados de Gestão HSEQ-RSC, Revisor de Pares da Elsevier, Revisor de Pares da Publons Academy e Advisor \& Peer Rewiever de Mendeley, Editor de Currículo em Revistas Acadêmicas - Minciencias. Líder da Seedbed de Pesquisa "Integradoss" e nomeado Professor Pesquisador da Escola de Ciências Básicas, Tecnologias e Engenharia ECBTI. Zona Caribenha, na Universidade Nacional Aberta e a Distância - UNAD. Email institucional Jairit.Garavit@unad.edu.co

Projeto de Pesquisa: ¿Cómo pesquisar em Educação virtual e a distância? 
Resume: O ambiente de trabalho moderno exige habilidades sociais dos trabalhadores, pois é aqui que eles devem trabalhar juntos. Desde um momento prematuro, é imprescindível aproveitar as habilidades do trabalho em equipe nos alunos, habilidades essas que se disseminam por meio da aprendizagem colaborativa. Este aprendizado é um ensino centrado no aluno. Um dos elementos mais importantes para a execução eficaz desta técnica nas escolas é a preparação de ambientes adequados para o uso da comunicação e habilidades sociais entre as pessoas, e uma orientação pedagógica correta e oportuna. O objetivo deste capítulo é apresentar as opiniões de professores e alunos sobre o método de aprendizagem colaborativa e as disposições desenvolvidas durante o curso dessas aplicações.

Palavras chave: Método de aprendizagem, orientação de professores, avaliação educacional, ensino colaborativo

Abstract: The modern work environment requires social skills from workers, as this is where they have to work together. From a premature time, it is essential to take advantage of the skills of teamwork in students, it is these skills that are disseminated through collaborative learning. This learning is student-centered teaching. One of the most transcendental elements for the effective execution of this technique in schools is the preparation of appropriate environments for the use of communication and social skills between people, and a correct and timely teaching orientation. The purpose of this chapter is to present the opinions of teachers and students on the collaborative learning method and the provisions developed during the course of these applications. This learning method depends to a great extent on the interdependence between the learners, and on the results as an important fragment of collaborative learning in its evaluation.

Keywords: Learning method, teacher orientation, educational evaluation, collaborative teaching

\section{Introdução}

Tanto os resultados de estudos nacionais como de pesquisas internacionais como Timms, Pirl e PISA revelam claramente a situação em nossos países e dizem que precisamos abandonar com urgência a compreensão tradicional da educação, que é uma transferência intensiva de informações que obriga os alunos a memorizar em nossa educação. . Nesse contexto, as etapas de reforma adotadas substituíram a abordagem de aprendizagem mecânica pela abordagem de educação centrada no aluno, ou seja, os métodos e técnicas em que o aluno é mais ativo podem construir conhecimento por si mesmo e se conectar com a vida tornam-se importantes, e esta compreensão pretende explicar aos nossos professores tanto nas nossas universidades como a serviço da sua profissão de educadores. 
Um dos métodos que coloca o aluno no centro é o método de Aprendizagem Colaborativa. Robert E. Slavin (1987) afirmou que a aprendizagem colaborativa como um conceito inclui metodologias educacionais nas quais os alunos são geralmente formados em pequenos grupos de 2, 3 e 4 pessoas e a competição em grupo é recompensada de maneiras diferentes. Enquanto Ac1kgoz (2003) o abordou como o processo de realizar a aprendizagem trabalhando em pequenos grupos e ajudando uns aos outros a aprender, e a revisão feita por Lin (2006) mostrou que é uma causa de ensino na qual os alunos se articulam para alcançar um objetivo comum sob a orientação do professor e trabalhar em pequenos grupos em um único método.

A aprendizagem colaborativa no sentido moderno começou em meados da década de 1960 (Johnson \& Johnson, 2002). Foi levantado contra o darwinismo social e o individualismo, que era apoiado naqueles anos, e essa resistência começou a ganhar aceitação no final da década de 1970, sendo geralmente preferida em todos os níveis de educação como método educacional. En comparación con los esfuerzos individuales y competitivos, la cooperación les permite tener más éxito en recordar mejor lo que se ha aprendido a largo plazo, ser capaces de pensar críticamente a un nivel superior, resolver problemas de manera más creativa, estar más dispuestos a alcanzar a meta. objetivo apesar das dificuldades, e transferir e usar seu aprendizado de uma disciplina para outra com maior sucesso (em comparação com os esforços individuais e competitivos). Johnson, Johnson \& Smith, 2007). Jigsaw I-II-III-IV, Mutual Questioning Method, com contribuições de Slavin, Kagan, Sharon e Cohen da década de 1980.

Em muitos estudos sobre aprendizagem cooperativa, observou-se que nossos professores confundem aprendizagem colaborativa com a técnica de ensino de trabalho em grupo. Os alunos que participam da aprendizagem procuram desenvolver ao máximo as suas próprias capacidades e as dos seus amigos. No entanto, em estudos de grupo, observa-se que os alunos trabalham separadamente em sua própria disciplina após compartilharem as disciplinas (Ac1kgoz, 2003). Johnson, Johnson e Holubec (1993). Portanto, a aprendizagem colaborativa pode ser melhor aplicada mencionando 10 fatores básicos.

\section{Endosso positivo}

Os alunos que se sentam juntos em pequenos grupos trabalham com consciência de suas necessidades mútuas para cumprir a tarefa dada pelo princípio de "Todos juntos ou nenhum de nós" e alcançar o sucesso. Para uma cooperação positiva, a capacidade do professor de distribuir materiais e tarefas apropriados é importante. É necessário atribuir tarefas adequadas às características individuais dos alunos e utilizar materiais que incentivem e ajudem as pessoas a pensar sobre o tema e a resolver problemas (Doymus, Simsek, \& Simsek, 2008). Recomenda-se que as pessoas trabalhem juntas por pelo menos 4 semanas para observar a solidariedade positiva dentro do grupo. 


\section{Instruções e conteúdo claros: realizações para o curso}

O conteúdo do curso e as atividades a serem realizadas durante o curso, os materiais a serem utilizados e a ordem em que serão apresentados devem ser claramente explicados aos alunos no início do curso pelo professor.

\section{Grupos heterogêneos}

O número ideal de pessoas em grupos é de 2 a 4 . Na criação de grupos, eles devem ser formados de forma heterogênea, levando em consideração as diferenças individuais. A saída da aprendizagem colaborativa é um dos pontos de interesse, e era a ideia de acabar com a discriminação com base na origem étnica na década de 1960. Para fazer isso, ao criar grupos heterogêneos, características como etnia, etnia, gênero, pontuações de desempenho acadêmico e uma distribuição equitativa. dentro de cada grupo deve ser assegurada.

\section{Paridade em proporções}

Embora existam diferenças individuais nos grupos, cada aluno deve ter as mesmas condições que todos os seus amigos para ter sucesso. Por ter sucesso, o indivíduo também deve aumentar o sucesso do grupo. De acordo com Slavin (1987), a avaliabilidade individual para aprendizagem em grupo, oportunidades iguais de sucesso e recompensas em grupo são necessárias para aumentar a eficácia.

\section{Interações}

Sentados em forma de meia-lua ou círculo, os alunos interagem sentando-se em uma posição onde os rostos são vistos e compreendidos sem levantar a voz. Quanto mais aumenta a interação dentro do grupo, mais senso de responsabilidade dos indivíduos para com os outros e para com o indivíduo, suas habilidades de raciocínio e dedução e, como resultado, a solidariedade social sobe para dimensões mais elevadas.

\section{Comportamento social}

A disposição dos assentos é um fator que aumenta a solidariedade social e a interação dos alunos, mas nem sempre significa que isso acontecerá. Os alunos devem demonstrar habilidades como liderança, confiança, gestão, crítica construtiva, respeito, senso de dever, incentivo, compromisso e adquirir essas habilidades sociais dentro do período de tempo em que estão no grupo. Se essas habilidades não puderem ser observadas durante a aula, o professor deve declarar claramente essas expectativas no início da aula. Os alunos gostam uns dos outros enquanto se esforçam para trabalhar juntos. Quanto mais se amam, mais querem trabalhar. Quanto mais pessoas 
trabalharem juntas, melhor será sua autoconfiança e saúde psicológica. À medida que as pessoas melhoram psicologicamente,

As pessoas que entram em relacionamentos mais sensíveis e conectados melhoram psicologicamente e, à medida que se recuperam, tendem a ser mais apegadas e sensíveis. A solidariedade social também tem um lado negativo. A solidariedade negativa existe quando as pessoas percebem que o caminho para atingir seus próprios objetivos será apenas através dos fracassos dos outros membros do grupo e os impedirá de atingir seus objetivos, o que inevitavelmente cria competição dentro do grupo. (Johnson, Johnson e Smith, 2007). o que inevitavelmente cria competição dentro do grupo.

\section{Período de tempo suficiente}

Indivíduos ou grupos precisam de um certo tempo para alcançar, compreender e construir o conhecimento científico. O professor deve dar aos alunos esse tempo ideal e nenhuma pressão de tempo deve ser criada. Caso contrário, o tempo limitado pode criar uma aprendizagem superficial ou uma incapacidade de aprender no indivíduo (Slavin, 1987-1990).

\section{Compromisso próprio}

Quando atribuímos alunos a grupos, cada aluno deve fazer o seu melhor; porque o sucesso do grupo depende do sucesso individual de cada peça do grupo. Para isso, os membros do grupo devem encorajar, apoiar e ajudar uns aos outros. Os membros do grupo devem explicar uns aos outros como resolveram os problemas que encontraram, discutir suas idéias com seus colegas de grupo e encorajar, apoiar e ajudar uns aos outros nessas questões. Desta forma, os membros contribuem para o sucesso dos outros.

\section{Habilidades próprias e de grupo}

Outro princípio básico da aprendizagem colaborativa é o ensino de habilidades sociais. Se o grupo formado com uma estrutura heterogênea não pode exibir habilidades sociais, nunca terá sucesso. O professor pode ensinar habilidades sociais, como a capacidade de trabalhar juntos, liderança, tomada de decisões, construção de confiança, comunicação clara e distinta e gerenciamento de condições adversas. Estudantes se conhecendo e confiando uns nos outros, aceitando e apoiando uns aos outros e resolvendo conflitos de forma construtiva aceleram a aquisição dessas habilidades. 


\section{Deliberação reflexiva do grupo}

Este processo inclui quais membros do grupo são úteis para alcançar a meta e se são ou não; quais comportamentos devem continuar no processo, o Inclui a avaliação dos processos para resolver o problema quando os alunos se deparam com um problema (Johnson \& Johnson, 2002). À luz destes princípios básicos, espera-se que o professor faça o seguinte em um ambiente de aprendizagem colaborativo:

- Planejamento de aulas, atividades e avaliação.

- Agrupamento de alunos.

- Organize a localização física dos alunos.

- Apresente e explique suas tarefas aos alunos.

- Supervisionar as atividades do grupo e intervir quando necessário.

- Ajude os alunos com habilidades sociais.

- Avalie os alunos (Flowers \& Ritz, 1994, citado em Timur, 2006).

Planos de aula e programas desenvolvidos à luz desses princípios permitem que os professores apliquem o método de aprendizagem colaborativa em suas salas de aula e permitem que os alunos em pequenos grupos cooperem uns com os outros com sucesso (Veenman et al., 2005).

Para que os alunos tenham sucesso com esse método, não basta que os alunos tenham conhecimento científico suficiente, se comuniquem efetivamente entre si, se encorajem, se treinem, usem o tom de voz adequado e esperem a vez (Nath \& Rose, 2001) intervir quando necessário. Quando olhamos para a literatura, podemos ver que existem duas divisões no que diz respeito às intervenções do professor no processo de interação entre os alunos. Segundo Kagan (1990; 1992), os professores argumentam que os alunos devem ter mais liberdade para assumir responsabilidades no processo de aprendizagem. Se um procedimento definitivo deve ser realizado, esses procedimentos devem ser baseados em balanças muito delicadas.

A perspectiva que emerge de Cohen (1992; 1994) é que as intervenções reduzem a quantidade de comunicação e cooperação dos alunos. Sugira que os professores usem a técnica de perguntas e respostas, na qual desenvolvam comentários e perguntas breves e depois se afastem do grupo para que o grupo possa continuar a discussão. Além disso, ela recomenda pequenas visitas para ajudar os alunos a se tornarem mais conectados, autodirigidos e confiantes (conforme citado em Chiu, 2004). Segundo Johnson e Johnson (2002), um dos possíveis motivos pelos quais os grupos não apresentam o sucesso desejado é que o professor não fornece a ajuda necessária quando necessário.

Nos casos em que os professores não dão as instruções na hora certa, observou-se que as competências sociais e a solidariedade de grupo esperadas nos alunos e, consequentemente, o sucesso individual e grupal não se encontram no nível pretendido Cohen, (1994), Chui (2004) assumiram que quando o modelo de intervenção do professor é usado corretamente, as práticas 
destemidas para dar resultados aos problemas dos alunos podem melhorar e a tarefa será concluída a tempo. O Modelo de Intervenção do Professor é definido como a intervenção dos professores no processo de aprendizagem colaborativa:

- De acordo com as necessidades dos alunos.

- Com foco em perspectivas conceituais e metodológicas.

- Combinando recursos de ensino e colegas.

Dekker e Elshout-Mohr, (2004) Facilito as do professor: Intervenção de ajuda ao produto: trata de chegar às respostas dos alunos e às conclusões dos dados. Intervenção de assistência ao processo: embora argumente que pode intervir de acordo com necessidades como chegar à aplicação entre pares e adaptar os processos de interação. Ding et al. (2007), por outro lado, estabelece que os professores devem ajudar os alunos em situações: quando nenhum aluno do grupo consegue responder à pergunta, quando os alunos têm dificuldade de se comunicarem entre si e quando um dos membros do grupo atua com autoridade sobre o de outros._Estudos têm mostrado que as referências do professor podem melhorar o comportamento do aluno durante e após a orientação.

O estudo Meloth \& Deering de 1992 mostrou que a orientação do professor influencia o comportamento subsequente dos alunos. Observou-se que após a efetivação do edital, os alunos discutiram mais, compartilharam mais informações e desenvolveram mais explicações do que antes do edital. Os professores podem fazer os alunos se concentrarem nos deveres de casa fazendo perguntas durante o estudo (Chui, 2004). Nessa literatura, destacam-se os estudos sobre os efeitos do treinamento colaborativo no desempenho acadêmico, atitudes e motivações dos alunos.

Aprendizagem colaborativa, sucesso acadêmico de estudantes universitários, retenção de memória, 2003; Yesilyurt, 2009), atitudes democráticas (Simsek, et al., 2004), preparação de tarefas com grupos (Doymuş, Bayrakceken \& Simsek, 2003), habilidades de processo científico aprimoradas (Bozdogan Tasdemir \& Demirbas, 2006) e habilidades gráficas de interpretação ( Tasdemir, Demirbas \& Bozdogan, 2006) alcançaram resultados mais positivos do que o método de ensino tradicional em que o estudo individual é importante.

Em estudos conduzidos com alunos do ensino médio, seu sucesso acadêmico no curso de estudos sociais, seu sucesso acadêmico no curso de ciência e tecnologia e suas atitudes em relação à ciência aumentaram (Gok et al., 2009; Senol \& Yıldırım, 2007). Num estudo realizado com alunos do ensino secundário por Keskin-Samanc (2006), tanto em termos de conhecimentos como de competências, No estudo de 2005 de Altıparmak e Nakipoğlu, laboratório de biologia. Concluiuse que teve mais sucesso nas aulas. 
$\mathrm{Na}$ parte final de alguns estudos, as atitudes dos professores foram expressas, mas as informações obtidas foram limitadas. As informações gerais e limitadas são insuficientes para fornecer uma perspectiva ampla e conhecimento aprofundado aos professores que realizam essas práticas em outras escolas. O valor do papel dos professores no método de aprendizagem colaborativa não foi totalmente refletido. Para proporcionar os benefícios mencionados, o objetivo deste compêndio em forma de capítulo é investigar a capacidade de conhecimento dos professores de sala de aula sobre o método de aprendizagem colaborativa e sua contribuição para o direcionamento do processo. As informações gerais e limitadas são insuficientes para fornecer uma perspectiva ampla e conhecimento aprofundado aos professores que realizam essas práticas em outras escolas.

\section{Padrão de pesquisa}

Neste estudo, foi utilizado um método de pesquisa qualitativa, incluindo um único estudo de caso aninhado. Os valores obtidos foram avaliados com base em uma análise de frequência.

\section{Universo de pesquisa}

A amostra da pesquisa foi selecionada por meio de um improvável método de amostragem intencional, 64 professores de salas de aula virtuais das escolas (faculdades) da Universidade Nacional Aberta e a Distância - UNAD. Além disso, 3 alunos bem-sucedidos e malsucedidos de cada classe foram selecionados aleatoriamente do terceiro e quarto anos de graduação da mesma universidade.

\section{Ferramentas de dados}

Nas entrevistas realizadas com autorização da direção da escola, foram incluídos na pesquisa 16 professores que responderam positivamente à questão "Você aplica o método de aprendizagem colaborativa? (Os professores foram codificados com letras) e após o objetivo da investigação foi explicado.

As observações foram feitas e gravadas, participando em 2 aulas expositivas na forma de blocos ministrados pelo método. Foi muito importante filmar a aula diante das câmeras para não perder os gestos e mímicas do professor durante a fala e em termos de confiabilidade das opiniões do professor. Após as aulas observadas, os professores responderam a perguntas de entrevista compostas por 10 perguntas semiestruturadas. $\mathrm{Na}$ etapa seguinte, o formulário de entrevista elaborado para os alunos selecionados, e as questões do formulário de entrevista do professor de acordo com o nível dos alunos, foram reforçados com 1 questão aberta sobre a aula ministrada. Uma vez obtidos os dados, as gravações das entrevistas foram transcritas e a análise de frequência realizada por meio da criação de categorias. 


\section{Resultados obtidos}

Embora apenas 3 de nossos professores tivessem alguma deficiência no sentido científico, os 13 professores restantes demonstraram que tentaram aplicar a técnica de discussão em pequenos grupos fazendo com que seus alunos se sentassem em pequenos grupos. Em geral, os temas do curso eram distribuídos aos grupos e cada um dos alunos do grupo responsável pelo tema do dia vinha ao quadro e explicava o tema que havia abordado. Durante esta conferência, outros grupos ouviram o assunto. Terminadas as aulas, o professor recompensou os alunos e o grupo que se prepararam bem para a disciplina, dando-lhes um reforço positivo. Ao final das palestras, a professora fez perguntas sobre o tema e o tema foi repetido e a aula encerrada.

A aula terminou com os alunos apresentando o tema teoricamente durante a maior parte da aula e o professor ouvindo silenciosamente como os outros alunos. Ao longo desse processo, a professora fez pouco uso de explicações que facilitassem o entendimento dos alunos. Apenas 4 professores deram as explicações necessárias. Ao final das apresentações dos alunos, os outros 9 professores tiveram o conteúdo preparado para os demais alunos, linha por linha. Na turma dos outros 3 professores, os alunos do grupo que explicaria o assunto explicaram a lição aos outros grupos (não a toda a turma), e os alunos do grupo de escuta tentaram aprender o assunto fazendo perguntas de os alunos que estavam conversando.

À medida que esse processo se desenvolvia, a professora percorria os grupos e enfatizava alguns rumos, principalmente os lugares importantes e o lugar do sujeito no cotidiano. No final das conferências, foram organizados concursos com uma técnica de perguntas e respostas ao estilo de jogo e distribuídos prémios (chocolate, tosta, chá, etc.). Nos últimos 5 a 10 minutos de aula, a professora fez uma rápida visão geral. Curiosamente, para a avaliação, que é uma das principais etapas na aplicação da aprendizagem colaborativa, não foi realizado nenhum exame informativo de tipo teste ou exame em nenhuma aula ao final do curso.

Após a aula observada, os professores responderam a perguntas abertas e suas opiniões foram determinadas. A primeira pergunta é: o que você faz no processo de aprendizagem colaborativa? Em consonância com as respostas obtidas, revelou-se que apenas 2 professores (turmas $\mathrm{A}, \mathrm{H}$ ) vieram preparados para a aula, ou seja, fizeram planos de aula antes da aula, criaram exemplos de aplicação e realizaram avaliações no final da aula. . para saber se aprenderam ou não. Além disso, todos os nossos professores afirmaram que acomodam os alunos em pequenos grupos em formato circular ou em U. E as principais opiniões dos professores sobre o Plano de Assentos são:

O professor daquela classe; Ele afirmou que durante o trabalho em grupo, eles não mudaram seu estilo normal de sentar em uma $U$, e os alunos que trabalhariam em grupos trocaram de lugar para ficarem próximos uns dos outros. Professor da classe I; Ele afirmou que prefere o arranjo em U como um plano de assentos, mas quando o método de aprendizagem colaborativa é aplicado, as 
filas são reunidas. Os 14 professores restantes afirmaram que se sentam em círculo durante a sessão de aprendizagem colaborativa.

A próxima pergunta é: você basicamente dá instruções nesse processo? Se você é estudante, que tipo de orientação você faz?, Todos os professores, exceto 1 professor (da classe H), afirmaram que orientam seus alunos durante o processo presencial. A nossa professora, que disse que não interveio, apresentou o porquê na aprendizagem colaborativa, os alunos têm de se autocontrolar, têm de se obrigar e motivar uns aos outros, para que eles próprios encontrem os comportamentos correctos, mas se sinto a dimensão de algum desacordo, é claro que vou intervir. Na sua opinião, qual deve ser a frequência e a duração dos encaminhamentos que você faz nessas etapas? Nas opiniões expressas na pergunta, afirmaram que a frequência de encaminhamento dos professores deveria ser $63 \%$ a mais e $30 \%$ a menos.

Tabela 1.

Frequência de indicação do professor

\begin{tabular}{|c|c|}
\hline Pouco extenso & Muito extenso \\
\hline $\begin{array}{l}\text { J e K: afirmou que o excesso de intervenção } \\
\text { restringe o aluno. } \\
\text { M: Se orienta com frequência, não traz muito de si, } \\
\text { o que moldou os alunos. } \\
\text { N: Eu só dou orientação sobre o uso e alocação de } \\
\text { recursos no início da lição. } \\
\text { EU: Não é correto intervir com muita frequência e } \\
\text { que as instruções variem de acordo com o aluno. }\end{array}$ & $\begin{array}{l}\text { PARA e B: são mais diretivos no que diz respeito } \\
\text { a recursos, devem ser avisados durante o trabalho } \\
\text { em grupo quando necessário. } \\
\text { C, D, E, I e Ou: a frequência da orientação deve ser } \\
\text { baseada nas necessidades dos alunos, os } \\
\text { professores devem estar na vanguarda durante a } \\
\text { fase de implementação e a orientação deve ser dada } \\
\text { nas outras fases. } \\
\text { F, G e I: Durante a aplicação, eles intervêm quando } \\
\text { necessário e devem ser muito orientados para que } \\
\text { possam se concentrar no assunto. }\end{array}$ \\
\hline
\end{tabular}

\section{Garavit, J. 2021}

De que forma você tenta criar e manter uma dinâmica de grupo? Quais são as reações dos alunos a isso? Todos os professores afirmaram que atentaram para a criação de turmas heterogêneas, que tentaram fazer no mínimo 1 aluno trabalhador e o mesmo número de gêneros nos alunos de cada turma, e que formaram turmas de 4 a 5 alunos no maioria. Além disso, para que o método de aprendizagem colaborativa seja bem-sucedido, a ideia comum de todos os professores é que ele deve começar desde a primeira série, pois é um processo de trabalho. Além disso, o professor da turma $\mathrm{G}$ afirmou que fazia turmas de dois ou três dependendo da atividade a ser realizada, e o professor da turma I afirmou que são 14 alunos em uma turma, sendo turmas de dois ou três cada. feito durante a experimentação.

O que você faz para incentivar os alunos em cada etapa? Você tem técnicas de suporte específicas para recompensar? À pergunta, todos os professores disseram que tratam bem os seus alunos e que procuram motivá-los sendo gentis e sem zangar-se. Explicações detalhadas são fornecidas na Tabela 2. 
Mesa 2.

Respostas de valor e recompensa

\begin{tabular}{|c|c|c|}
\hline Classe & Valor & Recompensa \\
\hline $\begin{array}{c}\text { DE } \\
\text { ANÚN } \\
\text { CIOS }\end{array}$ & $\begin{array}{c}\text { Durante a aplicação, os alunos que não passaram } \\
\text { também foram }\end{array}$ & Ele aplaudiu o grupo de sucesso na classe. \\
\hline EF & Incentivado ao tentar participar do estudo & Comportamento privilegiado em, gosto. \\
\hline OLÁ EU & E os alunos entre eles. & Portanto, os alunos reprovados ficam motivados. \\
\hline KL & Isso deve ser animado. & E que a dinâmica do grupo aumentou. \\
\hline AC & Em geral, os alunos autoconfiantes na sala de & Chocolate, chá, torradas, etc. prêmios. \\
\hline JG & É fácil porque é demais para você. & Deixo anotações especiais em seus cadernos de \\
\hline exames
\end{tabular}

Garavit, J. 2021

¿Cómo você faz com que os alunos expressem suas opiniões? As respostas à pergunta mostram que nossos professores preferem a técnica de brainstorming até $50 \%$ e tentam motivá-los com discussões e perguntas - respostas. No entanto, vemos que essas expressões verbais não refletem muito bem na filmagem da câmera, infelizmente. Nas imagens, observou-se que 11 professores $(68,75 \%)$ realizavam essas atividades com os alunos pouco ativos da classe, enquanto os demais alunos ficavam em silêncio e ouviam (Tabela 3).

Tabela 3.

¿Cómo você revela os pensamentos de seus alunos durante a colaboração?

\begin{tabular}{|c|c|c|}
\hline Itens por professores & $\begin{array}{c}\text { Professor } \\
\text { número }\end{array}$ & $\begin{array}{c}\% \\
\text { Faça perguntas a alunos individualmente }\end{array}$ \\
\hline $\begin{array}{c}\text { Ofereço ambientes confortáveis } \\
\text { Incentive os alunos a expressarem seus pensamentos, verdadeiros ou falsos. }\end{array}$ & 12 \\
\hline $\begin{array}{c}\text { Eu me certifico de que ideias diferentes surjam por meio do quadro de ideias e que } \\
\text { eles produzam argumentos ao mesmo tempo em que respeitam suas ideias. }\end{array}$ & 7 \\
\hline $\begin{array}{c}\text { Afirmou que apresentou ideias sobre o tema abordado e que os alunos pensaram } \\
\text { fazendo perguntas. Eu revelo (discussão socrática) }\end{array}$ & 1 \\
\hline $\begin{array}{c}\text { Ele revelou que os alunos nada fizeram para revelar seus pensamentos. } \\
\text { olhando para o trabalho dele }\end{array}$ & 3 \\
\hline $\begin{array}{c}\text { Ele se sente confortável porque não precisa lidar com alunos que são bons, porque } \\
\text { eles são confiantes }\end{array}$ & 2 \\
\hline
\end{tabular}

Garavit, J. 2021 
O professor $\mathrm{O}$ que você faz para compartilhar seus próprios pensamentos e comentários? Vemos que nossos professores se mantêm longe de reforçadores negativos e fornecem feedback aos alunos durante a aula e no final do curso. Tanto as gravações das câmeras quanto as notificações verbais mostram que nossos professores são ativos nesse aspecto. Além do reforço, os alunos que apresentam as informações recebem feedback citando fontes para obter informações mais detalhadas, destacando suas obras preferidas e exibindo-as pendurando-as no painel de parede (Tabela 4).

Tabela 4.

Compartilhe ideias e comentários

\begin{tabular}{|c|c|c|c|}
\hline & Itens de Ensino & $\begin{array}{c}\text { Número } \\
\text { professores }\end{array}$ & $\%$ \\
\hline \multirow{5}{*}{$\begin{array}{l}\text { Ao final } \\
\text { da aula }\end{array}$} & Seria melhor se você fizesse & 5 & 32 \\
\hline & Sistema de pontuação e / ou classificação & 2 & 12 \\
\hline & Uso de reforço positivo e menos reforço negativo & 7 & 44 \\
\hline & Com gráfico de desempenho (verificação) & 1 & 6 \\
\hline & Citação e exibição adicionais & 2 & 12 \\
\hline Na classe & Corrija erros durante a conferência & 8 & $\begin{array}{c}\text { cinquen } \\
\text { ta }\end{array}$ \\
\hline
\end{tabular}

Garavit, J. 2021

¿Cómo é garantida a igualdade nas referências feitas? Com a questão do Ser Democrático, todos os professores afirmaram que demonstravam um comportamento democrático em suas salas de aula e que esse era o fator mais importante para o professor, e que os alunos perceberam e estabeleceu-se a confiança mútua e uma sala de aula justa. o ambiente foi criado. Porém, as imagens das câmeras mostram que esse índice ainda é de 37,5\% (apenas 6 aulas). Embora os comportamentos democráticos sejam de alto nível, principalmente em turmas com turmas pequenas, essa taxa diminui à medida que aumenta o número de alunos em treinamento. Se o número de alunos for baixo, todos os alunos podem falar e expressar suas opiniões, enquanto a comunicação é elevada a níveis mais altos e em salas de aula lotadas,

O professor da classe $\mathrm{E}$ afirmou que tentou no início, mas foi um problema quando era difícil fazer uma promessa a todos devido à estrutura física e lotada da classe. Uma colaboração de qualidade Quais são os fatores mais importantes para o ambiente de sala de aula? Nas respostas dadas pelos nossos professores à questão, a curta duração do curso (75\%), a perspetiva proporcionada pelo programa (63\%) e as salas de aula lotadas consideram que isso é um problema. Eles também acreditam que o ambiente de sala de aula cooperativo desejado será criado se o professor cumprir suas responsabilidades. Além disso, observa-se que a comunicação professoraluno, aluno-aluno (25\%), que constitui a base da aprendizagem colaborativa, e a insignificância do nível do aluno (44\%) devido à formação de grupos heterogêneos, eles não podem ser suficientemente internalizados. por nossos professores (Tabela 4). 
Tabela 4.

De que depende a qualidade da orientação dada pelo professor?

\begin{tabular}{|c|c|c|}
\hline Itens do professor & $\begin{array}{c}\text { Número } \\
\text { professores }\end{array}$ & $\%$ \\
\hline professor & 7 & 44 \\
\hline Nível de estudante & 7 & 44 \\
\hline Relação professor-aluno & 4 & 25 \\
\hline Condições físicas da aula & 6 & 38 \\
\hline Número de estudantes & $11^{\circ}$ & 69 \\
\hline Programa & 10 & 63 \\
\hline Duração da aula & 12 & 75 \\
\hline
\end{tabular}

Garavit, J. 2021

Nas entrevistas realizadas com os alunos, que foram os outros pilares do estudo, a questão Quais são as semelhanças e diferenças entre os seus professores e o que pensam sobre o curso que ministram (estamos presentes) e os seus outros cursos? Na pergunta, percebe-se que os alunos gostam da aula colaborativa e isso os afeta positivamente. O interessante é que quando compararam com as aulas anteriores, não viram muito do que aconteceu na aula anterior (40 alunos, 83\%), e a maioria dos alunos comentou que as orientações de aprendizagem deveriam ser mais frequentes, para que podemos nos lembrar melhor. o que aconteceu na lição. Além disso, alguns alunos (8 alunos, 17\%) afirmaram que é melhor não receber ajuda dos professores.

Tabela 4.

Quais são seus pensamentos sobre a aula que você ensina com seus professores (em que estamos) e quais são as semelhanças e diferenças entre eles e suas outras aulas?

\begin{tabular}{|c|c|c|}
\hline Itens de professor & $\begin{array}{c}\text { Aluna } \\
\text { Número }\end{array}$ & $\%$ \\
\hline Divertido do que antes & 30 & 63 \\
\hline gratuitamente & 18 & 38 \\
\hline Animado & 16 & 33 \\
\hline Eles ajudam mais & 38 & 79 \\
\hline Nós conversamos e discutimos mais & 24 & cinque \\
nta
\end{tabular}

Garavit, J. 2021

Ao avaliar todas essas descobertas, não se deve esquecer que; À luz do aumento do comportamento não natural das pessoas observado em observações diretas, não seria errado comentar que, quando nossos professores têm câmeras na sala de aula, eles corrigem seu comportamento e embelezam sua fala. 


\section{conclusão}

Afirmaram que utilizavam o método de aprendizagem colaborativa em suas aulas. No entanto, observa-se que os alunos, em sua maioria, explicam o assunto em livros e realizam estudos de atividades em grupo. O processo é gerenciado na forma de compartilhamento de tarefas entre os membros do grupo para as atividades do livro, trabalhando por conta própria e com a intervenção do professor no meio. Além disso, houve poucas opiniões de que o trabalho em grupo teve um efeito positivo nas habilidades de demonstração dos alunos. Porém, no processo de aprendizagem colaborativa, há trabalho conjunto. No estudo de Erden de 1997, ele mostrou as etapas de aplicação do método de aprendizagem colaborativa da seguinte forma:

- Antes de começar a ensinar: Selecione o conteúdo, forme grupos, desenvolva materiais e instruções.

- Durante a instrução: Anunciar objetivos, apresentar informações, orientar, iniciar o trabalho em grupo.

- Depois de ensinar: Avaliação.

Quando olhamos para esses estágios, vemos que um ambiente de aprendizagem totalmente colaborativo não foi alcançado. Especialmente nas filmagens e entrevistas, nenhum dos professores falou sobre a educação por pares, que é um dos elementos mais importantes do método de aprendizagem colaborativa e seus benefícios. Enquanto os professores têm um raio de sucesso na formação de grupos, incentivando os alunos e exibindo comportamentos de ensino democráticos, as opiniões dos alunos enfatizam que isso só acontece por causa da câmera.

Neste método, o papel do professor é grande, para que seu trabalho seja eficaz e eficiente, as habilidades de comunicação entre os alunos devem ser de alto nível para uma orientação correta e oportuna para o trabalho. Segundo Johnson e Johnson (2002), um dos problemas encontrados é que o professor não fornece a ajuda necessária quando necessário. Chui (2004) afirma que quando o modelo de intervenção do professor é usado corretamente, as práticas de valor e soluções para os problemas dos alunos podem melhorar e a tarefa será concluída a tempo.

No estudo, os professores afirmaram que não deve haver muita orientação durante a aplicação em geral, e que só intervêm quando necessário. O professor deve intervir o mínimo possível enquanto os grupos estão trabalhando, mas isso não deve significar deixá-los sem supervisão. Neste estudo, muitos professores (13 professores) sentaram-se à mesa do professor enquanto os alunos estavam dando a aula, ouvindo-os e também passando algum tempo escrevendo algo em seus cadernos. Enquanto os grupos estão trabalhando, eles devem circular pelos grupos, estimular os alunos a perceberem as intervenções no trabalho de formação e orientar as equipes pedindo ajuda (apenas 3 professores tentaram fazê-lo). 
Este estudo mostrou que nossos professores ainda não abraçaram totalmente a essência da aprendizagem colaborativa, eles mostraram que não conseguiam entender a etapa de aplicação bem o suficiente e alguns deles até desistiram cedo.

Na literatura, este método é um dos métodos inevitáveis centrado no aluno, e os estudos agora usam subtécnicas (Jigsaw II-III-IV), Método de consulta mútua, Método de equipe de alunos (equipes), Jogos de equipes) em vez de questionar se este método é bom ou ruim ou seu efeito (o foco está em ensinar conceitos específicos com mira e tiro usando torneios). Esta pesquisa, que revelará como os professores se comportam e no que eles prestam atenção durante o coaching no processo de aprendizagem colaborativa, foi pensada para fornecer uma visão para aqueles que trabalham com esse tópico. 


\section{Referências}

Acikgoz, KU (2003). Aprendizado ativo, Publicações do mundo da educação, Editora de aprendizagem cooperativa nos laboratórios de biologia do ensino médio e $\mathrm{O}$ efeito do método na atitude e no sucesso. Jornal Turco de Ciências da Educação.

Arslan, O., Dogan-Bora, N. e Keskin-Samanc1, N. (2006). O efeito das técnicas de aprendizagem cooperativa na aprendizagem de alunos do décimo ano sobre o sistema nervoso. Estudos educacionais.

Bozdogan AE, Tasdemir, A. e Demirbas, M. (2006). O efeito do método de aprendizagem cooperativa no ensino de ciências no desenvolvimento das habilidades de processos científicos dos alunos. Jornal da Faculdade de Educação da Universidade İnonu.

Cohen, EG (1992). Reestruturação de salas de aula: condições para pequenos grupos produtivos. Wisconsin Center for Educational Research, Madison.

Cohen, EG (1994). Desenho do trabalho em grupo: estratégias para salas de aula heterogêneas. Nova York: Teachers College Press.

Chui, M. (2004). Adaptando as intervenções do professor às necessidades dos alunos durante o aprendizado cooperativo: como melhorar a solução de problemas dos alunos e o tempo gasto nos deveres de casa. American Journal of Educational Research.

Dekker, R. e Elshout-Mohr, M. (2004). Intervenções do professor com o objetivo de aumentar a proficiência matemática durante a aprendizagem colaborativa. Estudos educacionais em matemática.

Ding, M., Li, X., Piccolo, D. e Kulm, G. (2007). Intervenções do professor em aulas de matemática de aprendizagem cooperativa. The Journal of Educational Research.

Doymuş, K., Bayrakceken, S., Simsek, U. (2003). O efeito da lição de casa em grupo sobre o sucesso. Revista da Faculdade de Educação Kazim.

Doymus, K., Simsek, U. e Bayrakceken, S. (2004). O efeito do método de aprendizagem cooperativa no desempenho acadêmico e na atitude na aula de ciências, jornal turco de educação em ciências.

Doymus, K., Simsek, U. e Simsek U. (2008). Estudo de compilação do método de aprendizagem cooperativa: II. Aplicação do método de aprendizagem cooperativa em sala de aula. Revista da Faculdade de Educação Erzincan.

Gok, O., Dogan, A., Doymus, K. e Karacop, A. (2009). Os efeitos do método de aprendizagem cooperativa no desempenho acadêmico e nas atitudes de alunos do ensino fundamental. Gu, Gazi College of Education Journal.

Jigsaw, C. (2009). O efeito da utilização do método Jigsaw II na aula de ciência e tecnologia e o nível socioeconômico sobre o desempenho acadêmico, atitudes e níveis de motivação dos alunos para a aula de ciência e tecnologia. Dissertação de Mestrado, Zonguldak Karaelmas University, Zonguldak.

Johnson, DW e Johnson, R. T (2002). Aprendendo juntos e sozinhos: Visão geral e metaanálise. Asia Pacific Journal of Education. 


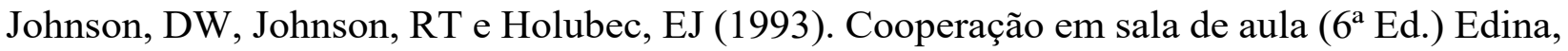
empresa Interação de livros.

Johnson, D., Johnson, R. e Smith, K. (2007). O estado da aprendizagem cooperativa em ambientes pós-secundários e profissionais. Journal of Educational Psychology.

Kagan, S. (1990). A abordagem estrutural da aprendizagem cooperativa. Liderança educacional.

Kagan, S. (1992). Aprendizado cooperativo. San Juan Capistrano, Ca.

Lin, E. (2006) Aprendizagem cooperativa na sala de aula de ciências. Professor de ciências. Maden, S. (2011). Elaboração das regras da técnica de torneio de jogo em equipe e sinaisn educação Uso de. E-International Journal of Educational Research.

Meloth, MS e Deering, PD (1992). Os efeitos de duas condições cooperativas nas discussões em grupo, compreensão de leitura e metacognição. Psicologia educacional contemporânea.

Nath, R. e Ross, S. (2001). A influência de um modelo de formação de tutoria entre pares para a implementação de grupos cooperativos com alunos do ensino fundamental. Pesquisa e desenvolvimento de tecnologia educacional.

Şenol, H. e Yıldırım, H.İ. (2007). O efeito do método de aprendizagem cooperativa no desempenho e na atitude dos alunos no processamento dos órgãos dos sentidos na aula de ciências da sexta série. Revista de Educação Kastamonu.

Simsek, U., Saturated, K., Simsek, U. \& Ozdemir, Y. (2004). Investigação do efeito do método de aprendizagem em grupo nas atitudes democráticas dos alunos. Revista da Faculdade de Educação Kazım Karabekir.

Simsek, U., Doymuş, K. e Kızıloglu N. (2005). Grupo para alunos do ensino médio Conhecimentos e habilidades adquiridas com o método de aprendizagem. Revista de Educação Kastamonu.

Slavin, RE (1987). Aprendizagem cooperativa: equipes de alunos, o que a pesquisa diz aos professores ( $2^{\mathrm{a}}$ ed.). Washington, DC: Associação Nacional de Educação.

Slavin, RE (1990). Métodos abrangentes de aprendizagem cooperativa: integração cooperativa Aprendizagem no currículo e na escola, aprendizagem cooperativa: teoria e pesquisa. Nova York.

Tasdemir, A., Demirbas, M. e Bozdogan AE (2006). O efeito do método de aprendizagem cooperativa no ensino de ciências no desenvolvimento das habilidades de interpretação gráfica dos alunos. Jornal da Faculdade de Educação GU Kirsehir.

Timur, S. (2006). O efeito do método de aprendizagem cooperativa no sucesso do aluno na aula de ciências da sétima série. Çanakkale: Instituto de Ciências Sociais. Projeto final de mestrado não publicado.

Webb, NM (1989). Interação entre pares e aprendizagem em pequenos grupos. Revista Internacional de Pesquisa Educacional.

Webb, NM e Farivar, S. (1994). Promover comportamentos de ajuda em pequenos grupos cooperativos em matemática do ensino médio. Journal of American Educational Research. 
Webb, NM, Troper, JD e Fall, R. (1995). Atividade construtiva e aprendizagem em pequenos grupos colaborativos. Journal of Educational Psychology.

Woodruff, E. e Meyer, K. (1997). Explicações do discurso intergrupo e intergrupo: alunos construindo conhecimento na sala de aula de ciências. Pesquisa em educação científica.

Veenman, S., Denesen, E., Akker, A. e Rijt, J. (2005). Efeitos de um programa de aprendizagem cooperativa nas elaborações dos alunos durante a busca e entrega de ajuda. Journal of American Educational Research.

Yesilyurt, E. (2009). Opiniões dos alunos sobre o efeito da aprendizagem cooperativa no comportamento dos alunos. Jornal de Ciências Sociais da Universidade de Firat. 